\title{
Impact of pollination environment manipulation on the apparent outcrossing rate in a Douglas-fir seed orchard
}

\author{
Y. A. EL-KASSABY*† \& R. DAVIDSON $\dagger$ \\ * Canadian Pacific Forest Products Ltd, Tahsis Pacific Region, Saanich Forestry Centre, 8067 East Saanich Road, RR\# 1, \\ Saanichton, BC VOS $1 M 0$ and $†$ Faculty of Forestry, University of British Columbia, Vancouver, BC V6T 1 W5 Canada
}

\begin{abstract}
The mating system of Douglas-fir [Pseudotsuga menziesii (Mirb.) Franco] was examined in two genetically similar seed orchard blocks with the aid of allozyme polymorphisms at six loci. The pollination environment (time of pollination and length of pollination season) of one block was manipulated by means of an overhead water spray cooling treatment. The cooling treatment temporarily delayed the pollination season in the treated block by 12 days relative to the untreated one. In addition, the length of the pollination season in the cooled block was shorter than the uncooled one by 12 days ( 18 vs. 30 days). The rate of inbreeding was significant in the uncooled block, while a perfect outcrossing rate was obtained for the cooled one. This difference was attributed to the low outcrossing rate obtained within the lower crown of the control block. It was concluded that the observed significant selfing in the uncooled block was caused by the firstpollination primacy that permitted related pollen to out-compete unrelated pollen in the extended pollination season. A shorter pollination season produced a dense pollen cloud of related and unrelated pollen, hence, early zygotic selection favoured unrelated embryos. An extended pollination season, on the other hand, permitted related pollen to succeed in pollination and fertilization without any challenge by unrelated pollen. Controllable variation in the rate of inbreeding reported in this study could be useful to improve the genetic quality of seed produced from seed orchards and consequently to maximize genetic gains from selections.
\end{abstract}

Keywords: Douglas-fir, outcrossing rate, pollen competition, pollination environment.

\section{Introduction}

The mating system, the union of male and female gametes and their genetic relationship, plays an important role in determining subsequent population structure and the dynamics of variation over generations (Wright, 1921). Due to its evolutionary and ecological significance, plant mating systems have been the subject of extensive theoretical and empirical work (cf. Schemske \& Lande, 1985, for review).

Coniferous forest tree species are wind-pollinated (Adams \& Birkes, 1990), among the most genetically heterozygous of plants (Hamrick et al., 1979), and often display strong inbreeding depression (Franklin, 1970). Seed orchards represent the link between the ongoing tree breeding activities and operational reforestation programme through the production of

Correspondence: Y. A. El-Kassaby. Canadian Pacific Forest Products Ltd, Tahsis Pacific Region, Saanich Forestry Centre, 8067 East Saanich Road, RR\# 1, Saanichton, BC V0S 1 M0. genetically improved seed crops. The extent to which orchard seed has both a high genetic quality and a broad genetic variability has been termed 'genetic efficiency' (Adams, 1983; El-Kassaby et al., 1984). High genetic efficiency is dependent upon the attainment of panmictic equilibrium through random mating (i.e. reproductive synchrony and equality among orchards' genetic entities) and reduced levels of selffertilization and pollen migration from extraneous sources.

Pollen migration (i.e. contamination) from extraneous sources reduces the genetic quality of seed crops and causes a reduction in the expected genetic gain. The manipulation of reproductive phenology development of seed orchard trees by overhead cooling has proved to be effective in reducing pollen migration (ElKassaby \& Ritland, 1986a). The cooling resulting from the water spray and evaporation causes floral bud burst to be delayed for a period of up to 2 weeks after local pollen release, hence avoiding pollen introgression 
from outside sources (Silen \& Keane, 1969; Fashler \& Devitt, 1980; Fashler \& El-Kassaby, 1987). It has also been observed that reproductive bud development progresses at a faster pace after the cessation of the cooling treatment and that the length of the pollination season is substantially shortened (El-Kassaby et al., 1984; Fashler \& El-Kassaby, 1987).

The shorter pollination season obtained following cooling may improve panmixis by making crossing possible among previously asynchronous clones (Fashler \& El-Kassaby, 1987). Shortening the pollination season increases the overlap of pollen release and ovule receptivity dates within crown and among related and unrelated genotypes (Fashler \& El-Kassaby, 1987). This reduction in the pollination season might affect the apparent outcrossing rates in two possible opposing directions. The first is to increase inbreeding levels within crown and among related genotypes (Erickson \& Adams, 1989). The second is to increase the outcrossing rates caused by reducing the amount of assortative mating between related individuals and/or by increasing the pollen competition between related and unrelated pollen.

This paper reports the results of a study of the mating system comparison between two genetically similar 13-year-old Douglas-fir [Pseudotsuga menziesii (Mirb.) Franco] seed orchard blocks. We asked whether the manipulation of the pollination environment alters apparent outcrossing, and whether this affect is influenced by the position of the female strobili in the crown.

\section{Materials and methods}

\section{Orchard description and blocks sampled}

Two genetically similar blocks from a 6 ha, full-sib Douglas-fir seed orchard provided material for this study. The orchard population consists of 110 full-sib families originating from controlled crosses conducted among grafts of 67 'plus trees' selected from natural stands on southern Vancouver Island and the south coastal mainland of British Columbia. Trees within the orchard's 14 blocks were planted in 1975 as 2-year-old seedlings in a systematic design (i.e. each family appears in the same position relative to other families within every block) using $4 \times 6 \mathrm{~m}$ spacing.

Cooling treatment was applied to seven blocks in the 1985 season commencing in the first week of February and ending in the last week of March (for a complete description of the cooling system, see Fashler \& Devitt, 1980). The reproductive phenology of the cooled blocks was temporarily delayed by 12 days relative to the uncooled block. The pollination season for both treatments ended on 30 April. Thus, the pollination period in the cooled part was compacted from 30 to 18 days in the uncooled part.

\section{Sampling procedure}

In the autumn of 1985 , cone samples were collected from every cone-bearing tree within two blocks, each representing cooled ( 72 trees) and uncooled ( 77 trees) treatments. Sampled trees' crowns were divided into upper and lower sections for cone collection. Each section contained cone samples from the north and south aspects. The identity of all cone lots and subsequent seedlots was retained for each tree within every block.

\section{Electrophoresis and estimation of outcrossing rates}

Electrophoretic procedures, staining recipes, and enzyme nomenclature followed methods reported by El-Kassaby et al.(1982b). The enzyme systems studied were: glucose-6-phosphate dehydrogenase (G6PD); isocitrate dehydrogenase (IDH); phosphoglucomutase (PGM); 6-phospho-gluconic dehydrogenase (6PGD); glucose-6-phospho-gluco-isomerase (PGI); and malate dehydrogenase $(\mathrm{MDH})$. The genotype of each tree was inferred for six allozyme loci (G6PD, IDH, PGM, 6PGD-1, PGI-2 and MDH-3) using the haploid megagametophyte of 40 seeds per tree with 10 seeds from each crown section. The genotypes of the corresponding diploid embryos of the 40 seeds per tree were simultaneously derived. The mode of inheritance and lack of linkage of these loci are reported by El-Kassaby (1981), El-Kassaby et al.(1982a,b).

For each treatment, multilocus estimates of the outcrossing rate $(t)$ were estimated using the multilocus mixed-mating model for megagametophytic conifer data of Ritland \& El-Kassaby (1985). Multilocus estimates were determined using the entire tree data and for the upper and lower crowns for each treatment.

\section{Results and discussion}

Estimates of the outcrossing rate ranged from a significant $(0.777)$ to non-significant $(1.065)$ departure from complete outcrossing $(t=1.0)$ (Table 1$)$. The estimates in Table 1 illustrate the following points:

1 the combined data estimated indicate that the outcrossing rate in the cooled block is significantly greater than that in the control block,

2 the observed differences between the control and cooled blocks is attributable to differences in outcrossing rate within the lower crown of the control block only, and 
3 four of the six estimates of outcrossing rate are significantly greater than 1.0 .

Estimates of outcrossing exceeding unity are common and have been reported in most mating system studies. Brown et al. (1985) identified either disassociative mating or sampling effects within the context of a valid mixed-mating model as the two primary causes for obtaining these 'biologically unreasonable' values. It should be noticed that all the outcrossing rate estimates obtained for the cooled block were greater than 1.0 (Table 1). This could be attributed to the success of the cooling treatment in increasing the mating probability among the phenologically more dissimilar individuals.

The complete outcrossing rate estimates obtained for the two crown strata and the combined estimate for the cooled block seem surprising. It is expected that under reduced phenological differences caused by the compaction of the pollination season, the overall crossfertilization may be decreased, since mating is promoted among related individuals and within crown. Erickson \& Adams (1989) called for a comparison between cooled and uncooled treatments for the same reason. If selfing is expected to be higher in cooled orchards than uncooled ones, then why did the results from this study show the opposite? And why was there a significant difference in the selfing rate between upper and lower crowns of the uncooled block and not in the cooled one?

Woods \& Heaman (1989) have reported the presence of a strong inverse relationship between the number of filled seeds per cone and various inbreeding levels in Douglas-fir. In their study, a substantial differ-

Table 1 Estimates of outcrossing (multilocus) and their $95 \%$ confidence intervals for seed samples collected from the upper and lower crown and their combined data from cooled and uncooled genetically similar Douglas-fir seed orchard blocks

\begin{tabular}{lll}
\hline & Cooled & Uncooled \\
\hline Upper crown & $1.039 \pm 0.005$ & $1.037 \pm 0.001$ \\
Number of trees & 69 & 76 \\
Number of seeds & 1258 & 1424 \\
Lower crown & $1.058 \pm 0.003$ & $0.972 \pm 0.021^{*}$ \\
Number of trees & 70 & 73 \\
Number of seeds & 1285 & 1375 \\
Combined data & $1.065 \pm 0.001$ & $0.977 \pm 0.013^{*}$ \\
Number of trees & 72 & 77 \\
Number of seeds & 2543 & 2801 \\
\hline
\end{tabular}

${ }^{*}$ Rejection of the null synthesis that $t=1.00$ at $P<0.05$. ence in mean filled seed per cone between selfing ( 1.2 seeds) and outcrossing ( 31.6 seeds) was reported. If the inbreeding level in cooled orchards is expected to be higher than in the uncooled ones, due to the compaction of the pollination season, then it should also be expected that the amount of inbred filled seed available for census is higher in the former than the latter. Consequently, higher levels of inbreeding should be detected in cooled orchards than uncooled ones if a large sample size is used. In the present study, a large seed sample size was intentionally used to address this point (Table 1). A comparison of the average filled seed set per cone between cooled and uncooled blocks failed to show any significant difference, indicating that a reduced seed set, due to the present selfing level in the orchard, is not a factor (El-Kassaby et al., 1990a). Furthermore, a comparison of the germination parameters and percentage of abnormal embryos between the two treatments also gave no significant differences (El-Kassaby et al., 1990b).

The amount and type (related or unrelated) of pollen and pollination timing are all important factors that affect the reproductive biology of Douglas-fir (Allen \& Owens, 1972; Owens et al., 1981; Owens \& Simpson, 1982). Douglas-fir, like most conifers, has ovules that bear several egg cells [4-6 eggs per ovule (Allen \& Owens 1972)]. Most of the eggs are fertilized by different male gametes generated from different pollen grains to produce embryos with different genotypes. Through early competition and selection only one embryo per ovule reaches maturity. It appears that the amount of pollen is one of the critical factors affecting the outcome of fertilization. If pollen is in limited quantity, ovules may contain only one pollen grain and would not benefit from the competition and selection.

First-pollination primacy in conifers was first hypothesized by Franklin (1974) and was demonstrated experimentally for Douglas-fir by Owens \& Simpson (1982) and Webber \& Yeh (1987). Webber \& Yeh (1987) have indicated that the effectiveness of the second pollination is lower than the first pollination, even when the second pollination occurs $5 \mathrm{~min}$ after the first pollination. Thus, it is apparent that the amount and type of pollen and the time of pollination all affect the genetic make-up of the seed produced.

In cooled orchards, the pollination period is compacted and the pollen production is high. Consequently, an adequate amount of related and unrelated pollen lands on receptive conelets. Therefore, competition and early zygotic selection favour outcrossed over selfed embryos. On the other hand, in uncooled orchards where the pollination period is extended (i.e. fewer males contributing at any one time), related pollen may have the chance to be the first 
to land. Consequently, related embryos can be produced even after competition and selection. The same situation applies for lower crowns in uncooled orchards, where selfed-pollen has a greater chance to be the first to land due to the relative position of male and female cones on the tree.

The compaction and delay in the pollination period following cooling was beneficial in reducing pollen migration from outside sources (El-Kassaby \& Ritland, 1986a) and in producing a homogeneous outcrossing pollen pool throughout the pollination season (ElKassaby et al., 1988). El-Kassaby \& Ritland (1986b) have demonstrated that pollen migration from outside sources has increased the observed outcrossing rate as every successful contamination event is an outcrossing rate event. Under cooling, the rate of pollen migration is minimized and the obtained high outcrossing rate in the treated block could only be explained by early zygotic selection that favoured the outcrossed embryos. In the uncooled orchards, if the rate of pollen migration is high, then the observed significant inbreeding is underestimated. In a study designed to estimate the temporal variation of the mating system over 3 years (1984-1986) (Y. A. El-Kassaby \& R. Davidson, unpublished observations), it was estimated that the rate of pollen migration to the studied uncooled block was very low or non-existent specifically for the 1985 season, thus providing a unique opportunity for comparison. Therefore, the observed significant $(P<0.05)$ selfing rate for the combined estimate, and more specifically the lower crown in the uncooled block, is caused by the selfed or related pollen primacy. The distribution of male and female cones in conifers (Sarvas, 1962) suggests that there may be crown stratum differences in the genetic composition of the pollen pool.

The outcrossing rates of several plant species have revealed marked differences under different environmental conditions (cf. Clegg, 1980, for review). This study represents the first report on the influence of pollination environment manipulation on the outcrossing rate. The observed significant increase in outcrossing rate in the cooled block represents an added practical significance to the cooling treatment in Douglas-fir seed orchards.

\section{Acknowledgments}

The authors would like to thank S. Friedman, K. Ritland and D. Schoen for reviewing the manuscript and the anonymous referee for constructive suggestions. This project was funded in part by the British Columbia Ministry of Forests, Research Branch; Section 88 numbers LS-02-073, NS-02-014 and OS-02-010.

\section{References}

ADAMS, w. T. 1983. Application of isozymes in tree breeding. In: Isozymes in Plant Genetics and Breeding, Part A., Tanksley, S. D. and Orton, T. J. (eds), Elsevier, Amsterdam, pp. 381-400.

ADAMS, W. T. AND BIRKES, D. S. 1990. Estimating mating patterns in forest tree populations. In: Biochemical Markers in the Population Genetics of Forest Trees, Hattemer, H. H. and Fineschi, S. (eds) SPB Academic Publishing bv, The Hague, The Netherlands (in press).

ALLEN, G. S. AND OWENS, J. N. 1972. The Life History of Douglasfir. Environment Canada, Forest Service, Ottawa.

BROWN, A. H. D., BARRETT, S. C. H. AND MORAN, G. F. 1985. Mating system estimation in forest trees: models, methods and meanings. In: Population Genetics in Forestry, Gregorius, H. R. (ed.), Springer-Verlag, Berlin, pp. 32-49.

CLEGG, M. T. 1980. Measuring plant mating systems. BioScience, 30, 814-818.

EL-KASSABY, Y. A. 1981. Genetic interpretation of malate dehydrogenase isozymes in some conifer species. $J$. Hered., 72, 451-452.

EL-KASSABY, Y. A., EDWARDS, D. G. W. AND COOK, C. 1990a. Impact of crop management practices on seed yield in a Douglasfir seed orchard. Silvae Genet., (in press).

EL-KASSABY, Y. A., EDWARDS, D. G. W. AND TAYLOR, D. W. 1990 b. Effect of water-spray cooling treatment on seed germination in a Douglas-fir seed orchard. New Forests, 4, 3-12.

EL-KaSSABY, Y. A., FASHLER, A. M. K. AND SZIKLAI, O. 1984. Reproductive phenology and its impact on genetically improved seed production in a Douglas-fir seed orchard. Silvae Genet., 33, 120-125.

EL-KASSABY, Y. A. AND RITLAND, K. 1986a. Low levels of pollen contamination in a Douglas-fir seed orchard as detected by allozyme markers. Silvae Genet., 35, 224-229.

EL-KASSABY, Y. A. AND RITLAND, K. 1986b. The relation of outcrossing and contamination to reproductive phenology and supplemental mass pollination in a Douglas-fir seed orchard. Silvae Genet., 35, 240-244.

EL-KASSABY, Y. A., RITLAND, K., FASHLER, A. M. K. AND DEVITT, W. J. B. 1988. The role of reproductive phenology upon the mating system of a Douglas-fir seed orchard. Silvae Genet., 37, 76-82.

EL-KASSABY, Y. A., SZIKLAI, O. AND YEH, F. C. 1982a. Linkage relationships among 19 polymorphic allozyme loci in coastal Douglas-fir [Pseudotsuga menziesii (Mirb.) Franco]. Can.J. Genet. Cytol., 24, 101-108.

EL-KASSABY, Y. A., YEH, F. C. AND SZIKLAI, O. 1982b. Inheritance of allozyme variants in coastal Douglas-fir [Pseudotsuga menziesii var. menziesii (Mirb.) Franco]. Can. J. Genet. Cytol., 24, 325-335.

ERICKSON, V. J. AND ADAMS, w. T. 1989. Mating success in a coastal Douglas-fir seed orchard as affected by distance and floral phenology. Can. J. For. Res., 19, 1248-1255.

FASHLER, A. M. K. AND DEVITT, W. J. B. 1980. A practical solution to Douglas-fir seed orchard pollen contamination. For. Chron., 56, 237-241.

FASHLER, A. M. K. AND EL-KASSABY, Y. A. 1987. The effect of water spray cooling treatment on reproductive phenology in a Douglas-fir seed orchard. Silvae Genet., 36, 245-249. 
FRANKLIN, E. C. 1970. A survey of mutant forms and inbreeding depression in species of the family Pinaceae. USDA Forest Service, Research Paper SE-61.

FRANKLIN, E. C. 1974. Pollination in slash pine: first come, first served. In: Proceedings of a Colloquium, Seed Yield from Southern Pine Seed Orchards, Kraus, J. (ed.) Georgia Forestry Center, Macon, GA, pp. 15-20.

HAMRICK, J. L., LINHART, Y. B. AND MITTON, J. B. 1979. Relationships between life history characteristics and electrophoretically-detectable genetic variation in plants. Ann. Rev. Ecol. Syst., 10, 173-200.

OWENS, J. N., SIMPSON, S. J. AND MOLDER, M. 1981. The pollination mechanism and the optimal time of pollination in Douglas-fir (Pseudotsuga menziesii). Can. J. For. Res., 11, 36-50.

OWENS, J. N. AND SIMPSON, S. J. 1982. Further observations on the pollination mechanism and seed production of Douglas-fir. Can. J. For. Res., 12, 431-434.

RITLAND, K. AND EL-KASSABY, Y. A. 1985. The nature of inbreeding in a seed orchard of Douglas-fir as shown by an efficient multilocus model. Theor. Appl. Genet., 71, 375-384.

SARVAS, R. 1962. Investigations on the flowering and seed crop of Pinus sylvestris. Comm. Inst. For. Fenn., 53, 1-198.

SCHEMSKE, D. W. AND LANDE, R. 1985. The evolution of selffertilization and inbreeding depression in plants. II empirical observations. Evolution, 39, 41-52.

SILEN, R. R. AND KEANE, G. 1969. Cooling a Douglas-fir seed orchard to avoid pollen contamination. USDA Forest Service, Research Note PNW-101, 10 pp.

WEBBER, J. E. AND YEH, F. C. H. 1987. Test of the first-on, first-in pollination hypothesis in coastal Douglas-fir, Can. J. For. Res., 17, 63-68.

woods, J. H. AND HEAMAN, J. C. 1989. Effects of different inbreeding levels on filled seed production in Douglas-fir. Can. J. For. Res., 19, 54-59.

WRIGHT, s. 1921. Systems of mating. II. The effects of inbreeding on the genetic composition of a population. Genetics, 6, 124-143. 